Check for updates

Montreal, Canada

Cite this as: $B M J 2020 ; 371: \mathrm{m} 4725$ http://dx.doi.org/10.1136/bmj.m4725 Published: 03 December 2020

\title{
White House demands to know how UK approved vaccine before FDA
}

\section{Owen Dyer}

The UK's approval of the Pfizer BioNTech covid-19 vaccine ${ }^{1}$ has ratcheted up the pressure on the US Food and Drug Administration (FDA) and its commissioner Stephen Hahn, who was called to the White House this week to explain why the US would not be first to distribute a vaccine.

Two anonymous senior administration officials told the news website Axios that Hahn had been summoned by White House chief of staff Mark Meadows because "there are some who are complaining the FDA is not working around the clock to get things approved." Hahn's request to conduct the meeting by telephone had been denied, they said, adding that the FDA commissioner would be asked to explain why, in mid-November, he spent a week "vacationing."

The hostile press briefing prompted an FDA statement, which said that following a potential exposure to coronavirus, Hahn "chose a remote location to quarantine and he continued working, as he has done throughout the pandemic. Hahn has worked every single day of this pandemic, including weekends, holidays, and more."

Hahn acknowledged in an interview with CBS on 2 December that he had been in "robust discussions" at the White House the day before, but declined to specify who he had spoken to. ${ }^{2}$

Once considered a Trump loyalist, Hahn angered the White House this summer by apologising for remarks he had made that overstated evidence supporting convalescent human plasma as a covid-19 treatment.

The FDA's authorisation of that treatment and of hydroxychloroquine in March-revoked in July-were widely seen as examples of the regulator bowing to political pressure. The experience left many at the agency determined to resist the administration's chivvying on a vaccine.

"Let me be clear-our career scientists have to make the decision and they will take the time that's needed to make the right call," Hahn told Axios before heading to the White House.

But with the US now seeing over 2000 covid-19 deaths a day, the White House is no longer alone in questioning the FDA. In his CBS interview, Hahn appeared to argue that the FDA's review was more thorough than that of the UK's Medicines and Healthcare Products Regulatory Agency (MHRA).

Asked why the UK had finished earlier, he said, "You'd have to ask them." He went on, "We're one of the few regulatory agencies in the world, if not the only one, that actually looks at the raw data from clinical trials. We're not going to take a summary from a company and take their conclusions and base our decision on that. We're going to crunch the numbers ourselves. It's why the rest of the world looks to us and our decision making, because our processes are so robust."

The MHRA's chief executive June Raine credited the UK regulator's "rolling review" process for the rapid turnaround, a claim supported by the chief medical officer of BioNTech, Özlem Türeci. Analysing preliminary data as it came in positioned the MHRA for a rapid sprint to the finish after the maker's 23 November final submission, Raine said. But Hahn, in his CBS interview, said the FDA's approach was no different, except that it was delving deeper into the data.

\section{US vaccine hesitancy prompts FDA caution}

Hahn also pointed to the high levels of vaccine hesitancy in the US. A hasty authorisation could damage public trust, he suggested, leading to lower uptake.

An FDA independent advisory committee will meet to consider the Pfizer BioNTech vaccine on 10 December, and another will review Moderna's vaccine on 17 December. No decisions will be made until then, said Hahn, although FDA rules require such meetings only before full approval, not before emergency use authorisation.

How long after these meetings authorisations could come is unclear. Robert Redfield, director of the Centers for Disease Control and Prevention, suggested a matter of hours, but Peter Marks, FDA vaccines chief, said the delay might be "a few weeks." Hahn would say only that a decision would come "very soon" after the meetings.

In practice, the "race" to approval may be more of symbolic importance than clinical relevance. A document obtained by CNN from Operation Warp Speed shows that the first US delivery of the Pfizer BioNTech vaccine is scheduled for 15 December, and of the Moderna vaccine for 22 December, nearly a week after their advisory committees meet.

For the majority awaiting a vaccine, the key bottleneck will be production, not approval. The US is scheduled to receive 40 million doses of the Pfizer BioNTech vaccine this month. The UK has secured 40 million doses of the vaccine with delivery staggered throughout 2020 and 2021.

Mahase E. Covid-19: UK approves Pfizer and BioNTech vaccine with rollout due to start next week. BMJ2020;371:m471.

2 This Morning CBS. Interview with FDA commissioner Stephen Hahn. 2 December 2020. www.facebook.com/CBSThisMorning/videos/1381368532203126. 